\title{
GEOLOGICAL PETROPHYSICAL EVALUATION OF YAMAMA FORIMATION SUBBA FIELD
}

Abdulameer T. Shnawa

South Oil Company

\section{$\underline{\text { Abstract }}$}

The main purpose of this study is to estimate hydrocarbon potentialities of Yamama Formation (Valanginian-Early Hauterivian) by using assessment technique links up between gamma ray spectrometry $\log s$ and other conventional open hole $\log$ for determining the petrophysical properties of Yamama units in Subba oil-field and oil water contact as well.

The Lower Yamama (YB); is considered the main reservoir unit, aptly composed of shallow high depositional energy levels of oolitic to bioclastic grainstone facies reflecting low clay-content, thus these properties had gave a fruitful chance as for immigrated oil to accumulate in the porous bodies of this reservoir units.
The non-improved petrophysical properties of upper Yamama member (YA) due to far-deep depositional conditions reflected by well-developed dense-compact subtidal open-shelf lagoonal benthic foram / algal wackestone facies and sparse-fossiliferous lime mudstone intercalated with bioclastic wackestone facies, are clearly displayed sedimentary intervals of high clay-content that is, the reduction potential depositional conditions are highly affected on these facies.

YB-unit have attained (22-29m) net pay thickness with porosity (9.35$10.9 \%)$ and water saturation ranged (40-40.6\%), whereas the YA-unit net-pay thickness is reached to (7.5$16.5 \mathrm{~m})$ with (6\% phi) and (35.3 
$\% \mathrm{Sw})$. The oil water contact at the lower Yamama member may assign at depth $3573 \mathrm{~m}$ (MSL) of southern dome on basis of electrical logs monitoring, well log interpretation and test results carried out the formation units.

\section{INTRODUCTION}

\subsection{GEOGRAPHY}

The Subba oil field is located in Thikar governorate, approximately $70 \mathrm{~km}$ southeast Nasriya city, figure geographically outlined by(650 000 - 670 000) easting and (3340 3410) northing on U.T.M scale.

\subsection{SURFACE GEOLOGY}

The studied area is a flat-plane region and arise $(10-50 \mathrm{~m})$ above sea level, declines towards the north and eastern north where the flood plains, part of region is covered by sands and gravels of Pleistocene Dibdibba terrain.

\section{$1.3 \underline{\text { TECTONIC }}$}

Tectonically, the region is located on the western edge of Mesopotamian basin as a part of Arabian platform, figure (2). This zone is recognized by a narrow anticlinal symmetrical structures with axial tend of NW-SE; the small sized structures of this region could be attributed to long distance of the zone from the main axis of tectonic movements. Yamama formation is the main lower cretaceous carbonate reservoir in southern Iraq.

The field geometry is clarified into symmetrical anticlinal structure with northern and southern domes, separated by shallow saddle, according to results of the last 3drilled wells, and the Yamama formation acquired (40m) structural closure. 


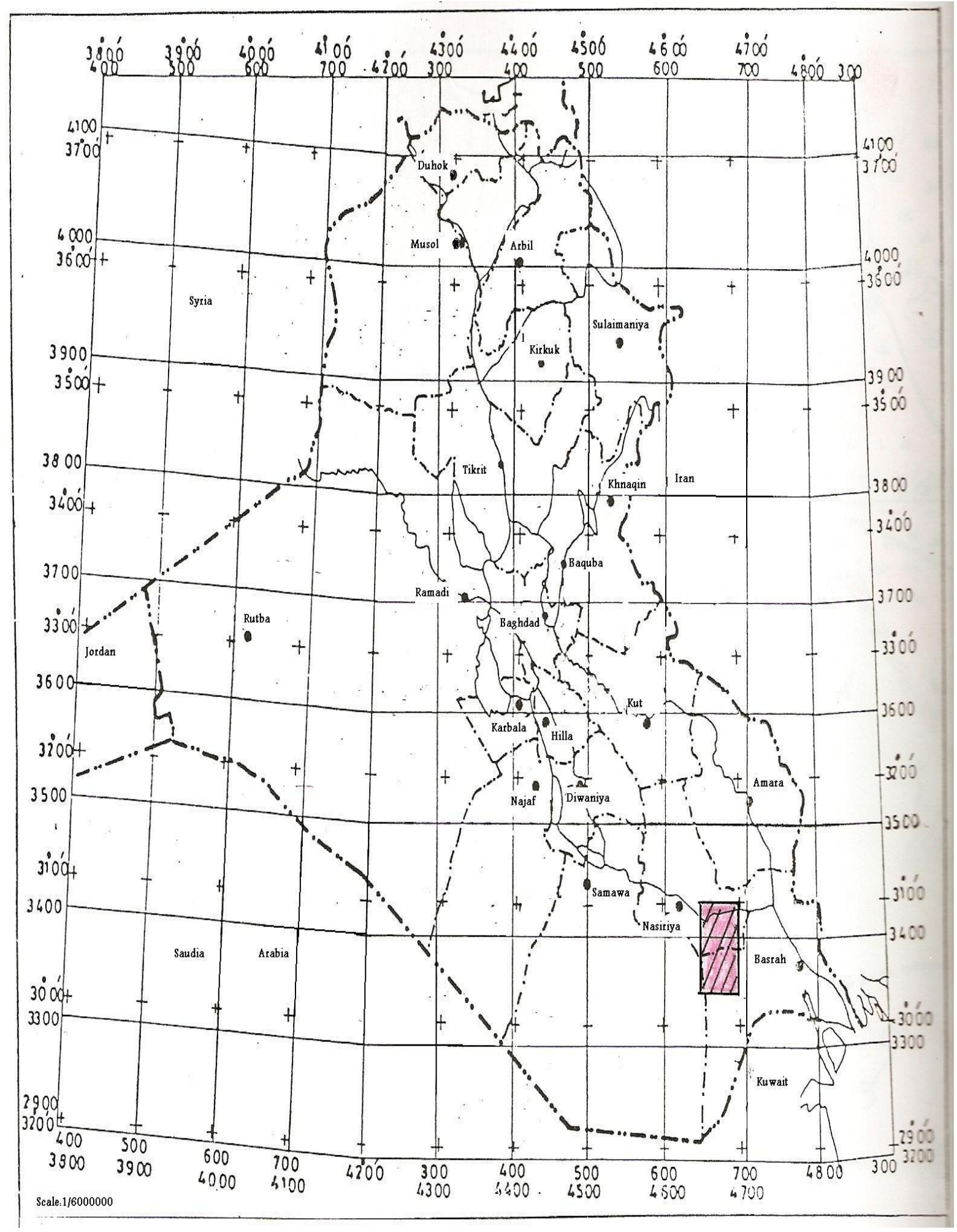

Fig (1) Geographical Location of Subba Field 


\section{Journal of Petroleum Research \& Studies}



Legend: L. Fault Anticline

Scale: $1 / 1000000$

Fig. (2) Tectonic Map of subba - Luhais Region, EOC 1989 


\section{GEOPHYSICAL SURVEYS}

The first geophysical survey was implemented by gravity method in the end of 1940s, when the gravity survey was applied to cover the Iraqi regions. The gravity residual map figure (3), created by Brown (1960), reflect two negative anomalies located on axis compatible with structural axis of Subba structure.

Legend:

Positive Anomaly

Negative Anomaly

Contour Lines

Contour Interval $=0.5$

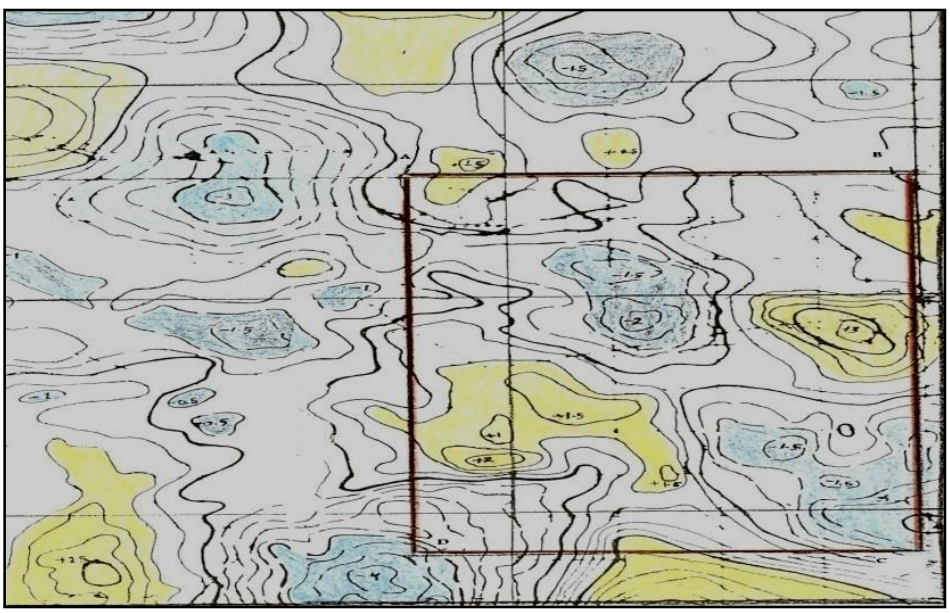

m.gal

Scale: $1 / 715000$

Fig. (3): Gravity Residual Map, Subba - Luhais Region,

Reference: Atlas of geophysical Activities

Two magnetic ground survey was carried out at end of 1970s by France Geophysical company, figure (4-A) whereas the second one was aerially accomplished during 1974, figure (4-B).

The seismic surveys, carried out during 1954 by Ray geophysical 


\section{Journal of Petroleum Research \& Studies}

company at the expense of the Basra

Oil Company, showed simple anticlines with structural noses, the work was accomplished in 1957 by S.S.L Company showed structural nose with $\mathrm{N}-\mathrm{S}$ axis.

Legend:

Positive Anomaly

Negative Anomaly

Contour Lines

Contour Interval = 10 Gamma

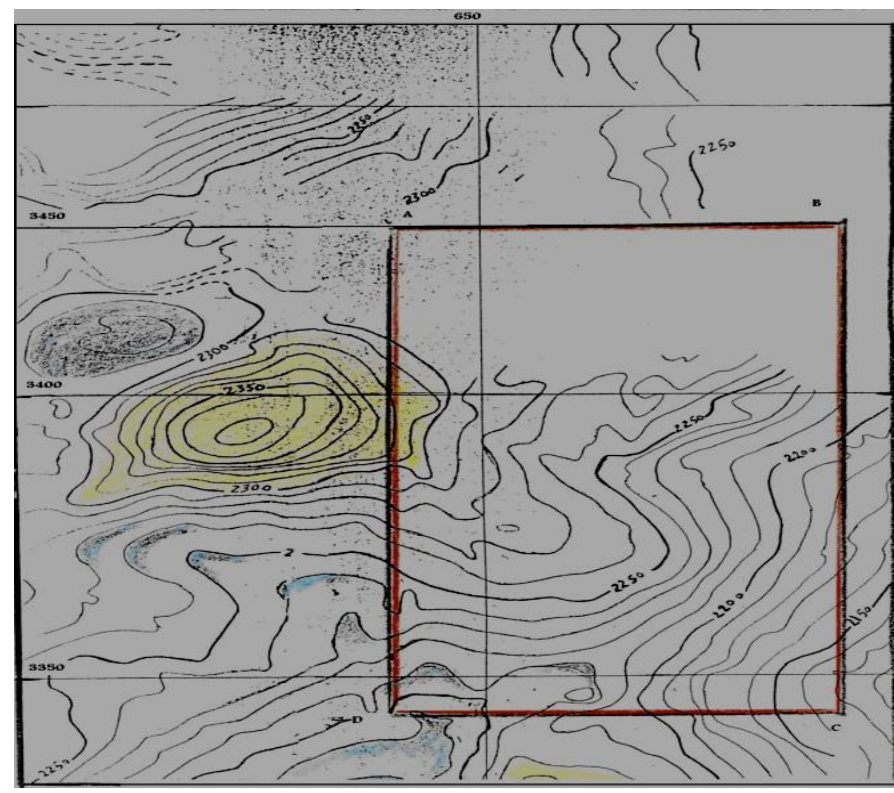

Scale : 1/ 715000

Fig.(4-A)Magnetic survey Map, Reference: Atlas of geophysical Activities

Legend:

Positive Anomaly

Negative Anomaly

Contour Lines

Contour Interval $=1.0$

Gamma

Scale : $1 / 715000$

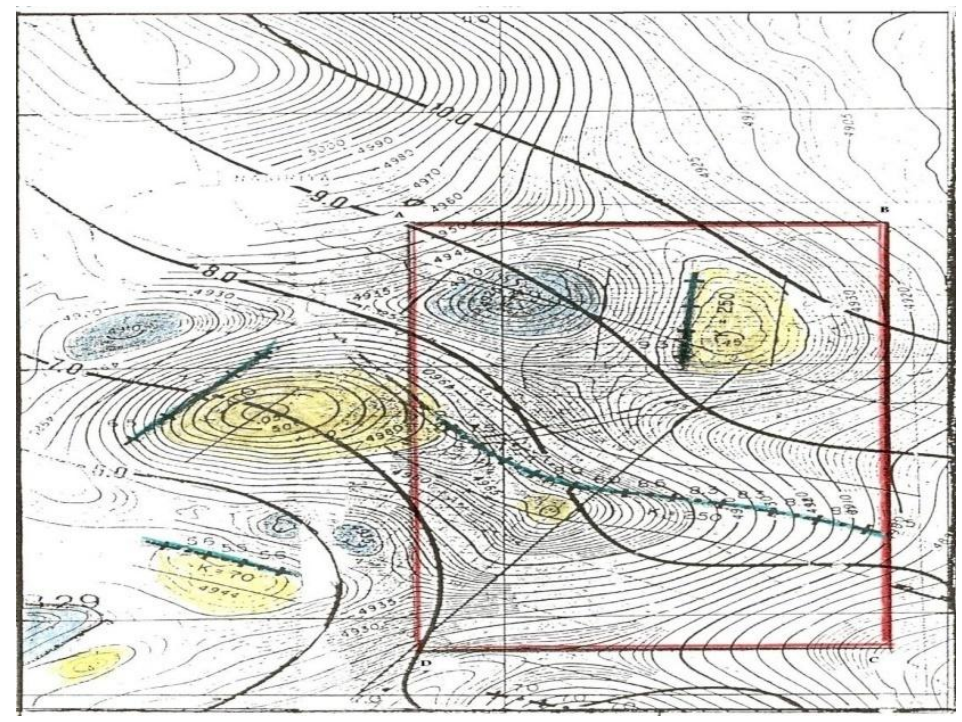

Fig. (4-B) Aerial Magnetic Survey, Reference: Atlas of geophysical Activities 
During (1972-1973) the Third Iraqi Seismic Group was executed a seismic survey; high-lightened a Subba anticline of long structural nose with closure of N-S axis.

After drilling the first and second exploration wells during 1974, the previous seismic data re-processed by Oil Exploration Company (OEC) using computer software, and revised maps were performed a newly Subba structure picture of main N-S trending northern dome contains three closures, and southern dome separated by a clear structural saddle. Since (1977-1978) three wells were drilled (Su- 3,4,5), accordingly; the geological results re-interpreted and executed in 1979 a structure aptly considered longitudinal anticlinal structure consists of two main domes with $\mathrm{N}$ $\mathrm{S}$ axis, separated by shallow structural saddle.

During $(1979-1980)$, the $9^{\text {th }}$ Iraqi Seismic Group was carried out seismic surveys on Subba - Luhais region showed that, the depth contour map of Shuaiba, Gotnia and Najma formations in a two main domes (northern \& southern) with $\mathrm{N}-\mathrm{S}$ axis , separated by a saddle and the northern dome itself forms two minor domes ,one of them is close up and the other is open towards the north. In (1984) the northern part of Subba field was surveyed, the results showed that the northern dome trends in the direction of NW-SE with structural-nose. Two exploration wells (Su-7, 8) were drilled during 1985-1986, to assess Yamama formation; hopeful and optimistic results were gained. In (1988), the Subba - Luhais seismic interpretation practice was implemented specially after (Su-9) positive drilling-results, by which a new seismic picture of the Subba structure came into reality; specified by two N-S trending domes with common closure. 


\section{Journal of Petroleum Research \& Studies}

By comparing; the two seismic studies 1988 figure (5), and 1992 figure (6); issued by $\mathrm{OEC}$, the structural geometry had gave anticlinal structure with N-S dual dom-

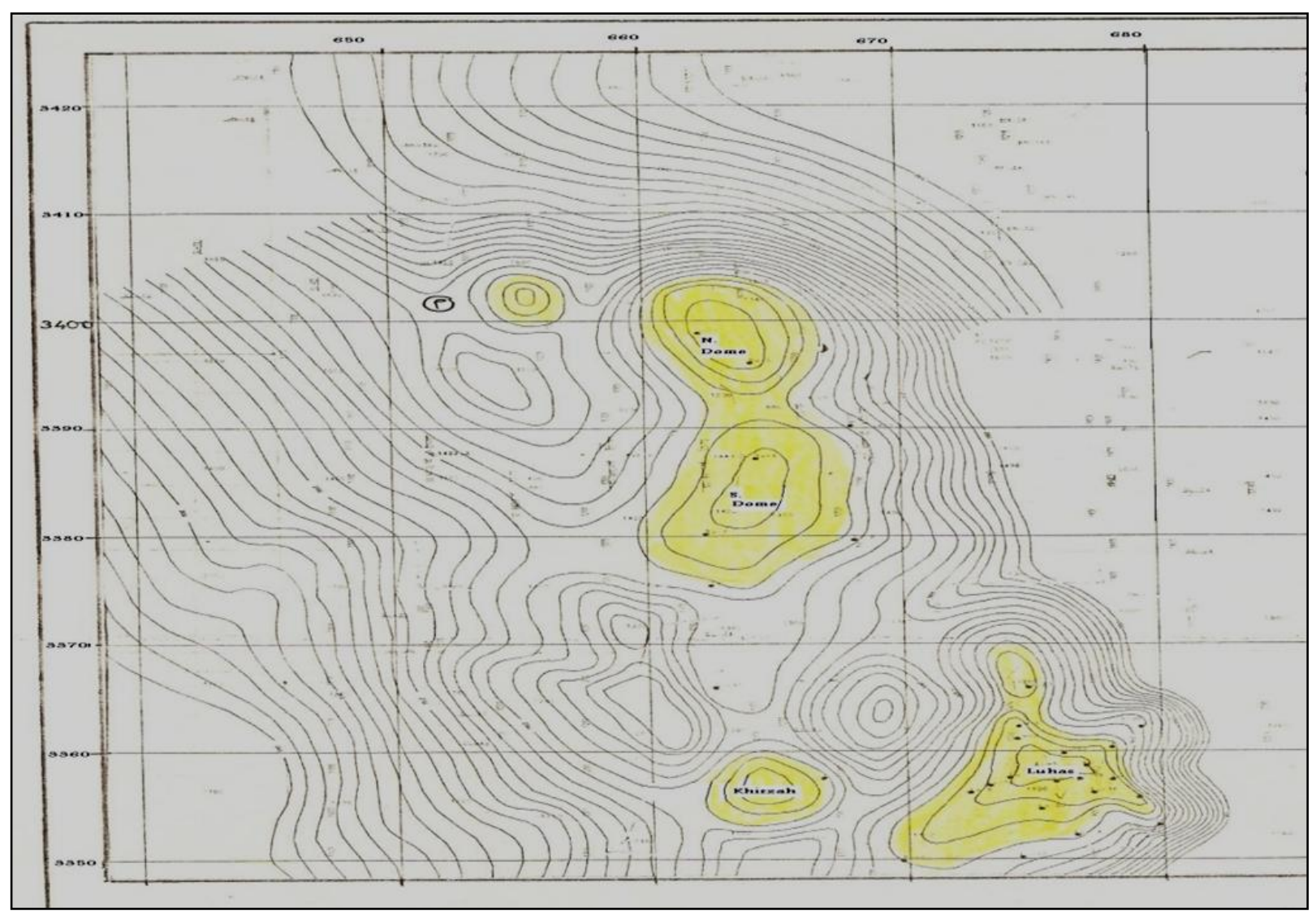

Fig (5) Structure Contour Map on top of Zubair Formation, EOC -1988 


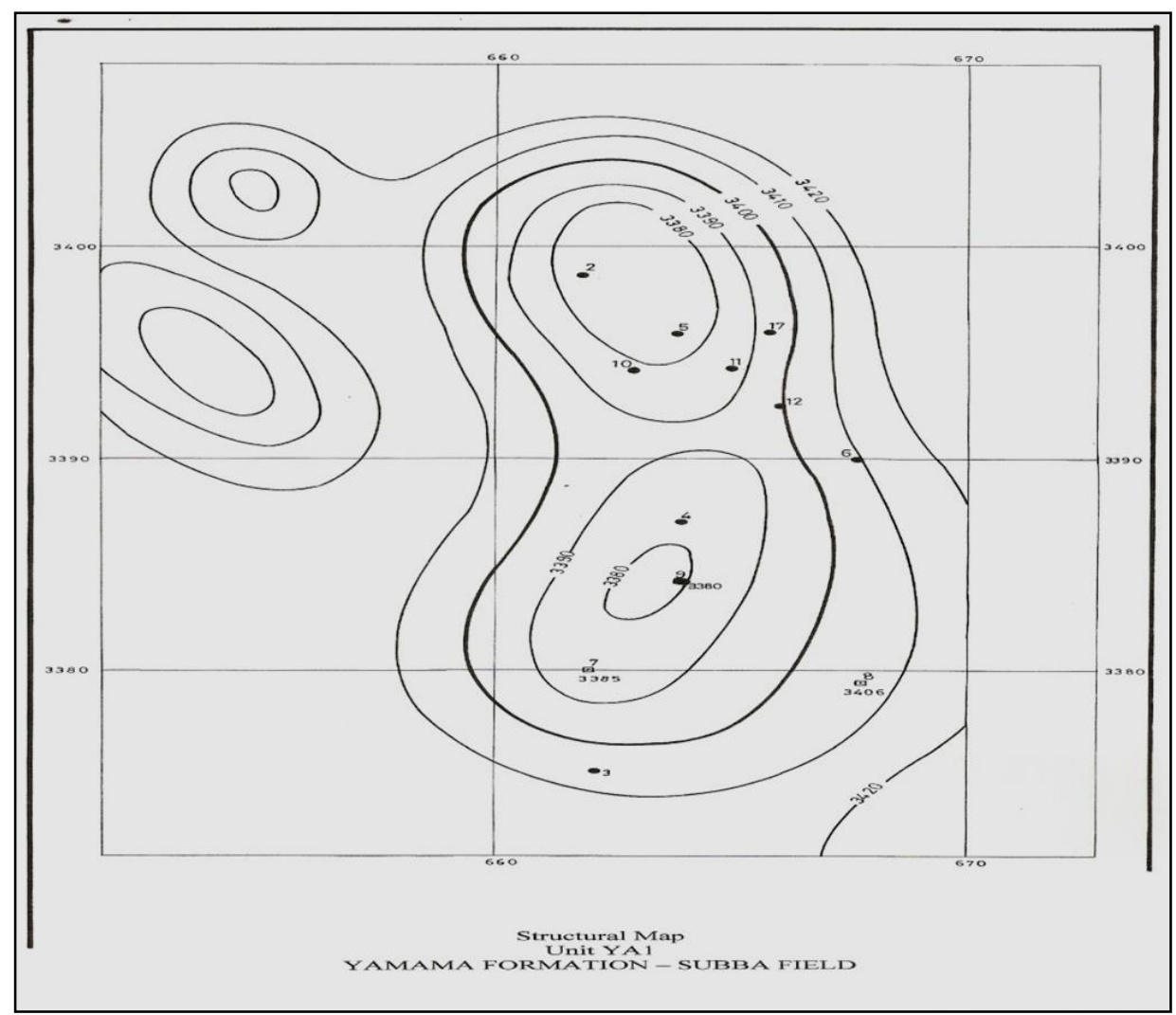

Fig. (6) Structure Contour Map on top of Yamama Formation, EOC -1992

es, the southern one contains the wells (Su-3, 4,7,8 \& 9), whereas the northern one contains the wells (Su2, 5, 10.11 and12).Table 1 lists the well data in Subba Field.

The structure on top of Yamama formation shows, the southern dome attains low dip angle $\left(1 / 2^{0}\right)$ than the northern dome where the dip angle reaches $\left(1^{0}\right)$, the dimensions of southern dome (target of the study) could be approximated by

$(17 \times$ $10 \mathrm{~km})$ and the structural closure close to $40 \mathrm{~m}$. 


\section{Journal of Petroleum Research \& Studies}

Table 1: Subba field well-data

\begin{tabular}{|c|c|c|c|c|c|}
\hline $\begin{array}{c}\text { WELL } \\
\text { NO. }\end{array}$ & $\begin{array}{c}\text { Drill. } \\
\text { History }\end{array}$ & $\mathrm{RTKB}(\mathrm{m})$ & NORTHING & EASTING & $\mathrm{TD}(\mathrm{m})$ \\
\hline $\mathrm{Su}-1$ & 1974 & 55.10 & 3365720.5 & 662265.3 & 2839.60 \\
\hline $\mathrm{Su}-2$ & 1975 & 7.50 & 3398633.3 & 661833.3 & 3189.00 \\
\hline $\mathrm{Su}-3$ & 1977 & 36.20 & 3375248.6 & 662167.9 & 2899.00 \\
\hline $\mathrm{Su}-4$ & 1978 & 18.54 & 3387000 & 664000 & 2812.70 \\
\hline $\mathrm{Su}-5$ & 1978 & 8.70 & 3395870 & 633850 & 2810.00 \\
\hline Su-6 & 1980 & 21.16 & 3390000 & 667750 & 2866.00 \\
\hline $\mathrm{Su}-7$ & 1985 & 31.46 & 3380000 & 662000 & 3729.00 \\
\hline $\mathrm{Su}-8$ & 1985 & 40.13 & 3379450 & 667800 & 3775.00 \\
\hline $\mathrm{Su}-9$ & 1988 & 24.67 & 3384385 & 664450 & 3715.00 \\
\hline Su-10 & 1989 & 11.05 & 3594292.56 & 663293.67 & 2840 \\
\hline Su-11 & 1989 & 13.08 & 3394397.28 & 665290.93 & 2850 \\
\hline Su-12 & 1989 & 19.68 & 3392719.78 & 666379.83 & 2869 \\
\hline Su-13 & 1989 & 18.38 & 3390938 & $665 \quad 472.28$ & 2864 \\
\hline Su-14 & 1989 & 21.1 & $3389 \quad 307.7$ & $664 \quad 641.4$ & 2850 \\
\hline Su-15 & & & 3389359.28 & 666497.51 & water well \\
\hline Su-16 & 1990 & 13.78 & $3392 \quad 614.75$ & 662382.63 & 2860 \\
\hline Su-17 & & & 3395985.44 & 665843.12 & \\
\hline
\end{tabular}




\section{STRATIGRAPHY}

\section{The Yamama formation} originally defined by (M.Steinke and R.Bramkamp 1952) from a surface section in Saudi Arabia as a fragmental limestone, aged to early cretaceous and determined to Thamama Group. In southern Iraq it was defined by (P. Rabanit 1952) in Ratawi field (Rt-1) where the top has taken at the beginning of a thick oolitic limestone, it is overlain conformably by Ratawi formation and underlain by Sulaiy formation, and a brief description in the Iraq geologic lexicon (Dunnington 1959) where it was described under a combined entry with the Sulaiy formation (Alsadooni 1993).

The Yamama formation is belongs to the late Berriasian-Aptian cycle which represented from shore to deep basin by the Zubair, Ratawi, Garagu-Yamama, Shuaiba, Sarmord and lower Balambo formations (Buday 1980), the stratigraphic relationships of Yamama formation are illustrated in figure (7).

During late Jurassic, the transgressive phase started and deposited sub-basinal clayeycarbonates represented by Sulaiy formation (Remond 1964, Alsidiki 1978), this transgression continued to Early Berriasian. A regression took place during the Late Berriasian and continued upto Late Hauterivian finally resulted a succession of Yamama carbonates and Ratawi carbonate/shaly-shale facies.

Southern Iraq region has been divided by (Fulloria 1976) into three main areas according to physiographical - sedimentlogical system based on a general framework of the ramp, during Late Berriasian - Early Hauterivian sedimentary succession, the Yamama carbonates were deposited throughout the provinces from north eastern region of the development scheme of the ooliticpseudoolitic/peloidal facies. 


\section{Journal of Petroleum Research \& Studies}

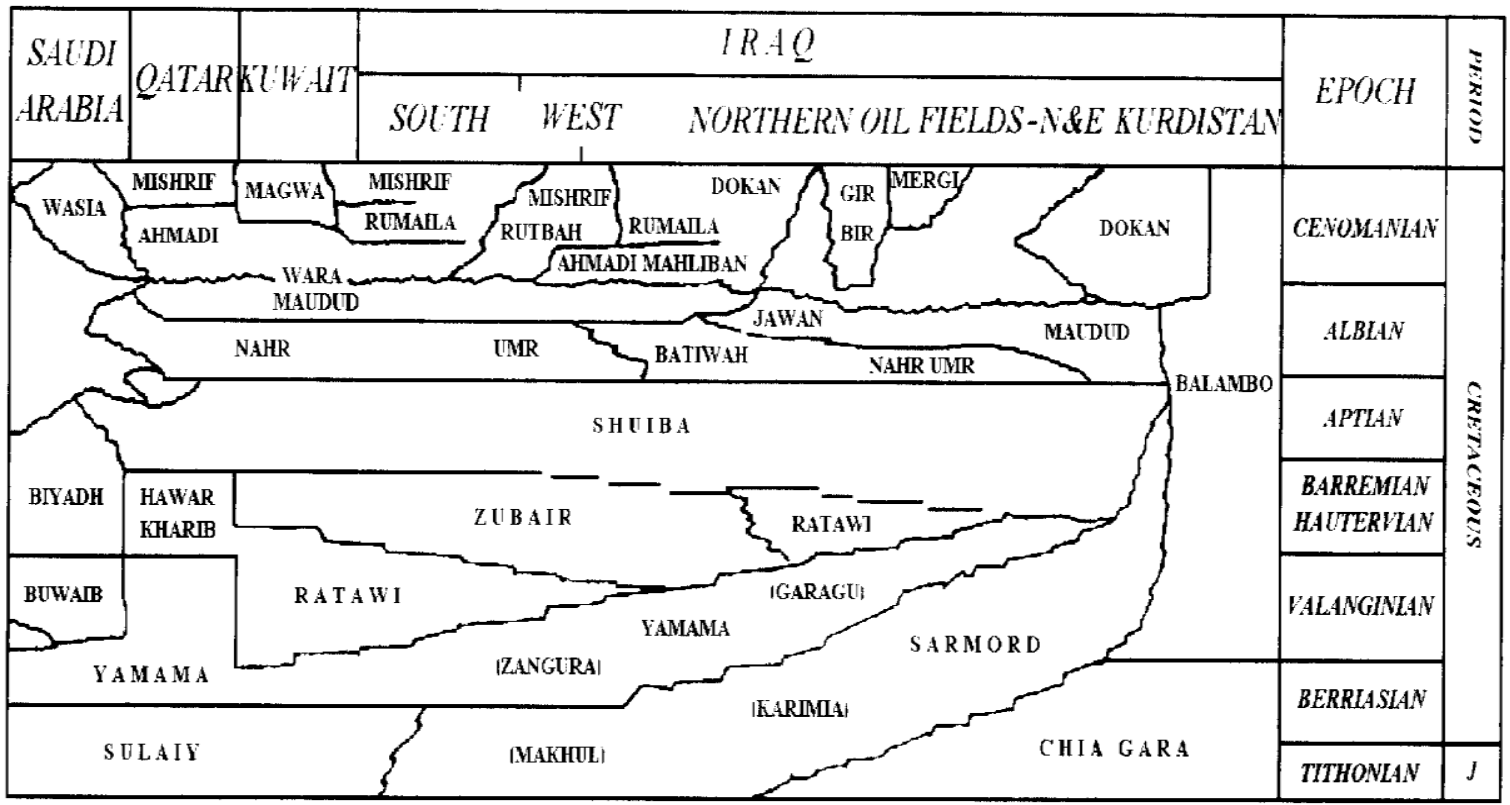

Fig (7) Stratigraphic relationship of Yamama formation and its equivalents in Iraq and neighboring countries, OEC archive

Saudi Arabia, Kuwait and southern Iraq, obviously profiled within carbonate ramp

with regional dip stretching towards the east-northeast territories; the succession gradually prograded into different shallow to open depositional realms of Yamama formation (Razoian A.M. 1995). Where the members were deposited under major regressive stratigraphicpackage mainly progressed from outer-ramp setting to shallow (middle - inner ramp settings).
In consideration of radioactive minerals distribution practice interpreted from gamma ray spectrometry in especially accordance with the Sonic and SPlogs data, it is possible to distinguish the representative lithological units of each member with respect to the petrophysical properties and welltest results carried out on the reservoir units, figure (8) table( 2).

The study divided the formation into two members; upper Yamama YA and lower Yamama YB, figure (9A, 
B), on the basis of the conventional and radioactive logs.

\subsection{UPPER YAMAMA MEMBER} $\underline{(\mathrm{YA})}$

The thickness of this sedimentary unit almost equally distribute on Subba field (southern dome) which ranges from (85-89 $\mathrm{m})$. It is clearly clarified that this unit could be recognized with high readings levels of natural gamma ray which also accompanied by high levels of uranium spectra that recovered by NGS log which exceed (2 ppm), in-clear separation between potassium and thorium curves.

It should be noted that the uranium as a radioactive element highly associate with other radioactive elements in excess of shale, so it is not a fixed indicator for shale volume if we take it alone (Serra, 1972). The characteristic properties indicate that this zone deposited in a restricted-open shelf lagoonal environment not effected by tide waves due to feebleness of depositional energy that highly produced elevated amounts of clay materials. The sonic log readings show strictly low porosity levels versus high resistivity encountered by induction log. Open-shelf lagoonal facies are suitably represent the depositional intervals of this member (six units), and will be given in-details in the reservoir geology chapter.

\subsection{LOWER YAMAMA MEMBER} $\underline{(\mathrm{YB})}$

The member ranged from (70 to $78 \mathrm{~m}$ ) in thickness, it is recognized by low radioactive rates recorded by NGS except some of few thin beds at the upper portion of this member affected by facies change especially these close to open shelf setting. Low proportions of radioactive sigma reflected by low concentration of uranium spectra with approximate 
merging of potassium and thorium

curves. The high porosity readings

of sonic logs ; is good indicator for these properties of upper yamama member .

This zone of Lower Yamama member reflects highly agitated depositional energy levels within shallow ramp profile of oolitic and pseudoolitic packstone/grainstone facies.This member was divided into eight stratigraphic units separated by th three massive impervious calcareous barriers 


\begin{tabular}{|c|c|c|c|c|c|c|c|}
\hline \multicolumn{2}{|c|}{$S u-7$} & \multicolumn{2}{|c|}{$S u-8$} & \multicolumn{2}{|c|}{$\mathrm{Su}-9$} & \multirow{3}{*}{ Unit } & \multirow{3}{*}{$\frac{\dot{\Xi}}{\sum}$} \\
\hline$K B$ & & \multicolumn{2}{|c|}{$K B(40.1)$} & \multicolumn{2}{|c|}{$K B(24.67)$} & & \\
\hline Interval & 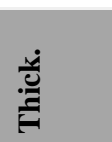 & Interval & : & Interval & 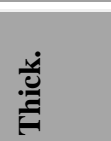 & & \\
\hline $3416-3437$ & 21 & $3446-3468$ & 22 & $3404.5-3427$ & 22.5 & YA1 & YA \\
\hline $3437-3445$ & 8 & $3468-3476$ & 8 & $3427-3432$ & 5 & Barr.1 & \\
\hline $3445-3456$ & 11 & $3476-3487$ & 11 & $3432-3442$ & 10 & YA2.1 & \\
\hline $3456-3463$ & 7 & $3487-3495$ & 8 & $3442-3449$ & 7 & Barr.2 & \\
\hline $3463-3488$ & 25 & $3495-3552$ & 17 & $3449-3474$ & 25 & YA2.2 & \\
\hline $3488-3505$ & 17 & $3522-3541$ & 19 & $3474-3491$ & 17 & Barr.3 & \\
\hline $3505-3535$ & 30 & $3541-3574.5$ & 33 & $3491-3517$ & 26 & YB1 & YB \\
\hline $3535-3562$ & 27 & $3574.5-3605.5$ & 31 & $3517-3550$ & 33 & Barr.1 & \\
\hline $3562-3579$ & 17 & $3605.5-3616.5$ & 11 & $3550-3557.5$ & 7.5 & YB2.1 & \\
\hline $3579-3593$ & 14 & $3616.5-3641$ & 24.5 & $3557.5-3582$ & 24.5 & Barr.2 & \\
\hline $\begin{array}{l}3593- \\
3608.5\end{array}$ & 15.5 & $3641-3661$ & 20 & $3582-3597$ & 15 & YB2.2 & \\
\hline $\begin{array}{c}3608.5- \\
3627\end{array}$ & 18.5 & $3661-3677.5$ & 16.5 & $3597-3616$ & 19 & Barr.3 & \\
\hline $3627-3649$ & 22 & $3677.5-3697$ & 19.5 & $3616-3629$ & 13 & YB3 & \\
\hline $3649-3719$ & 70 & $3697-3775$ & 78 & $3629-3707$ & 78 & Barr.4 & \\
\hline
\end{tabular}

Table (2) Zoning of Yamama formation on Subba field 


\section{Journal of Petroleum Research \& Studies}

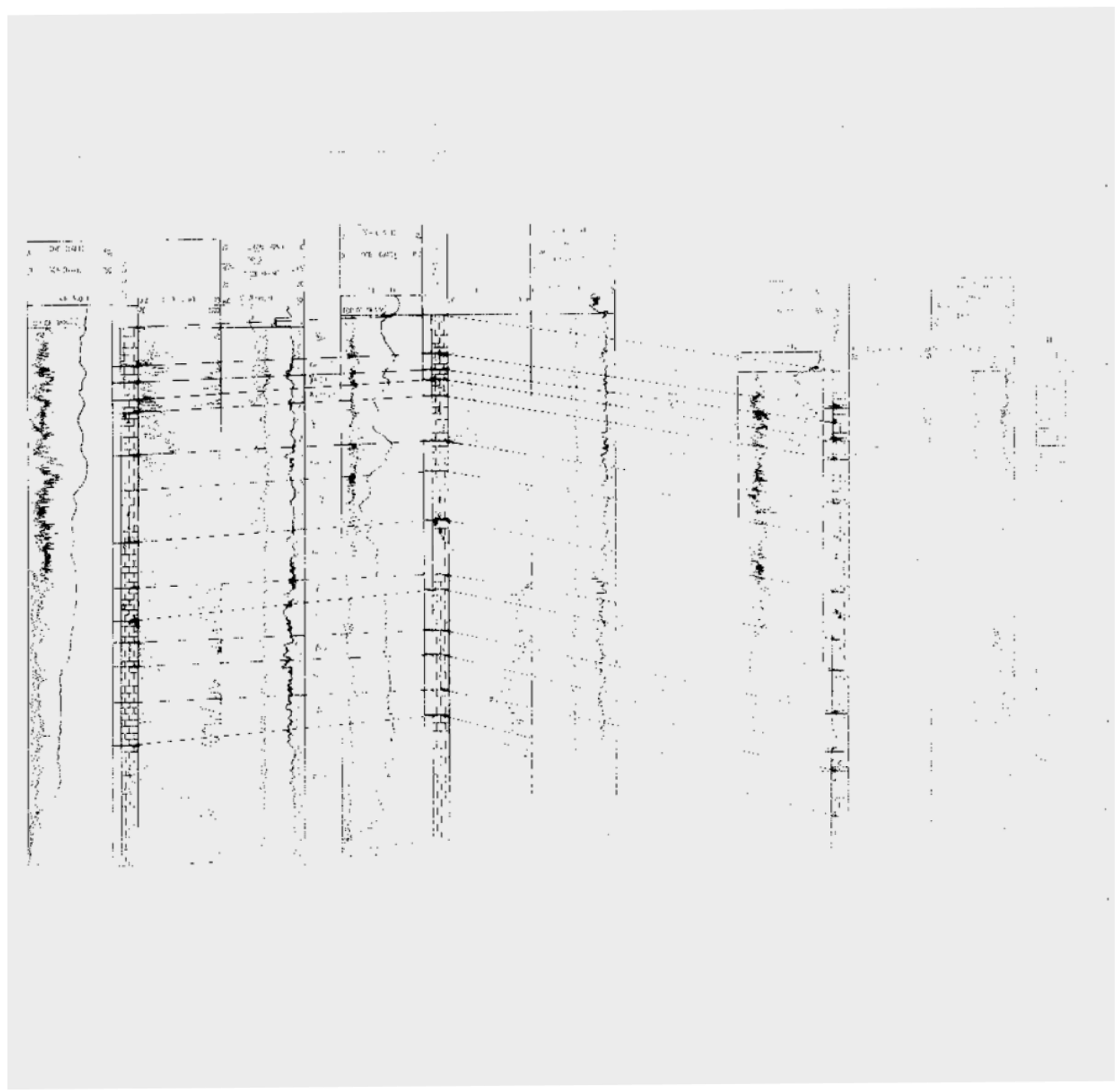

Fig (8) Structural-Stratigraphic Section along Yamama wells - Subba Field 


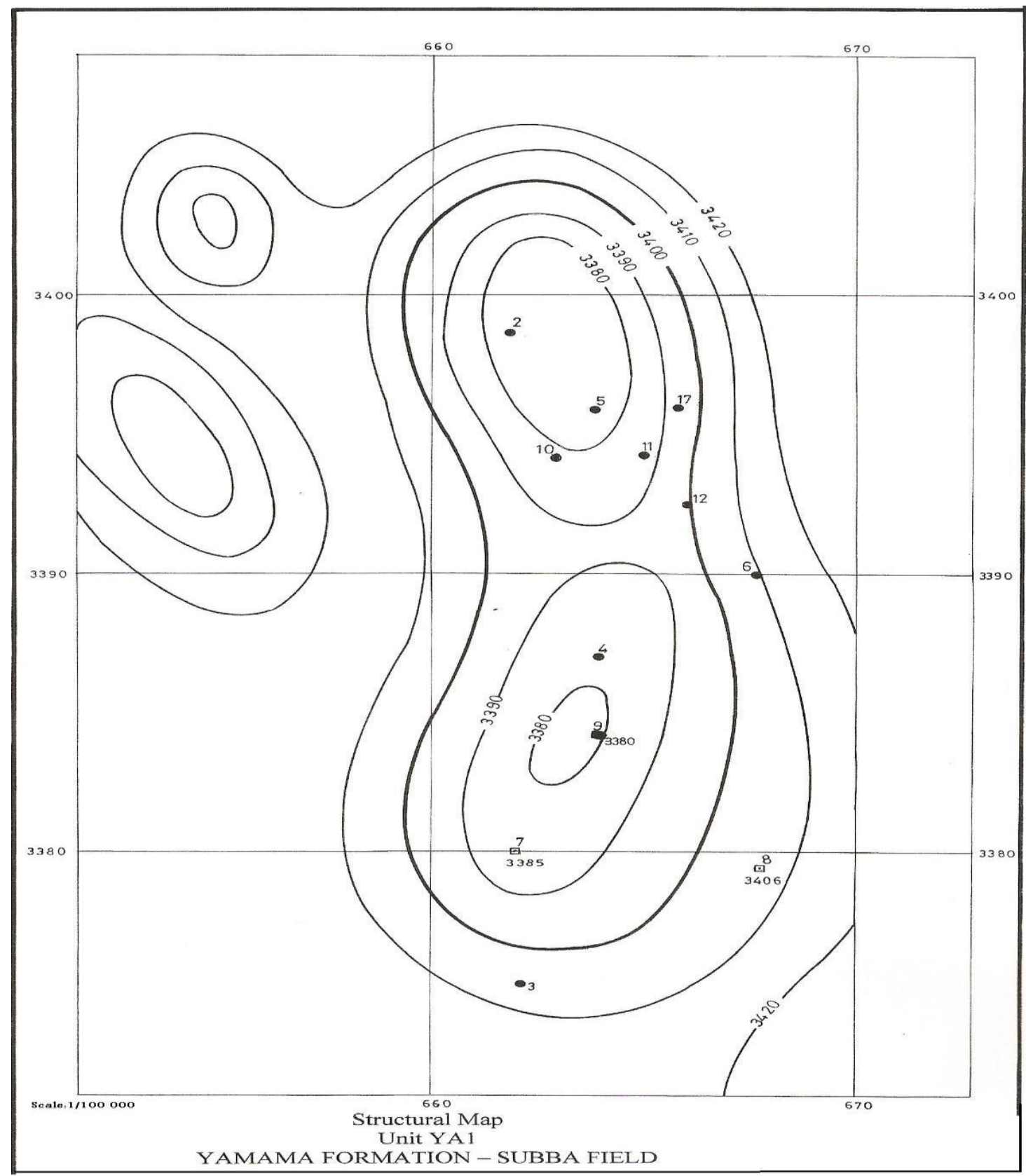

Fig (9A): Structure Contour Map on top of 


\section{Journal of Petroleum Research \& Studies}

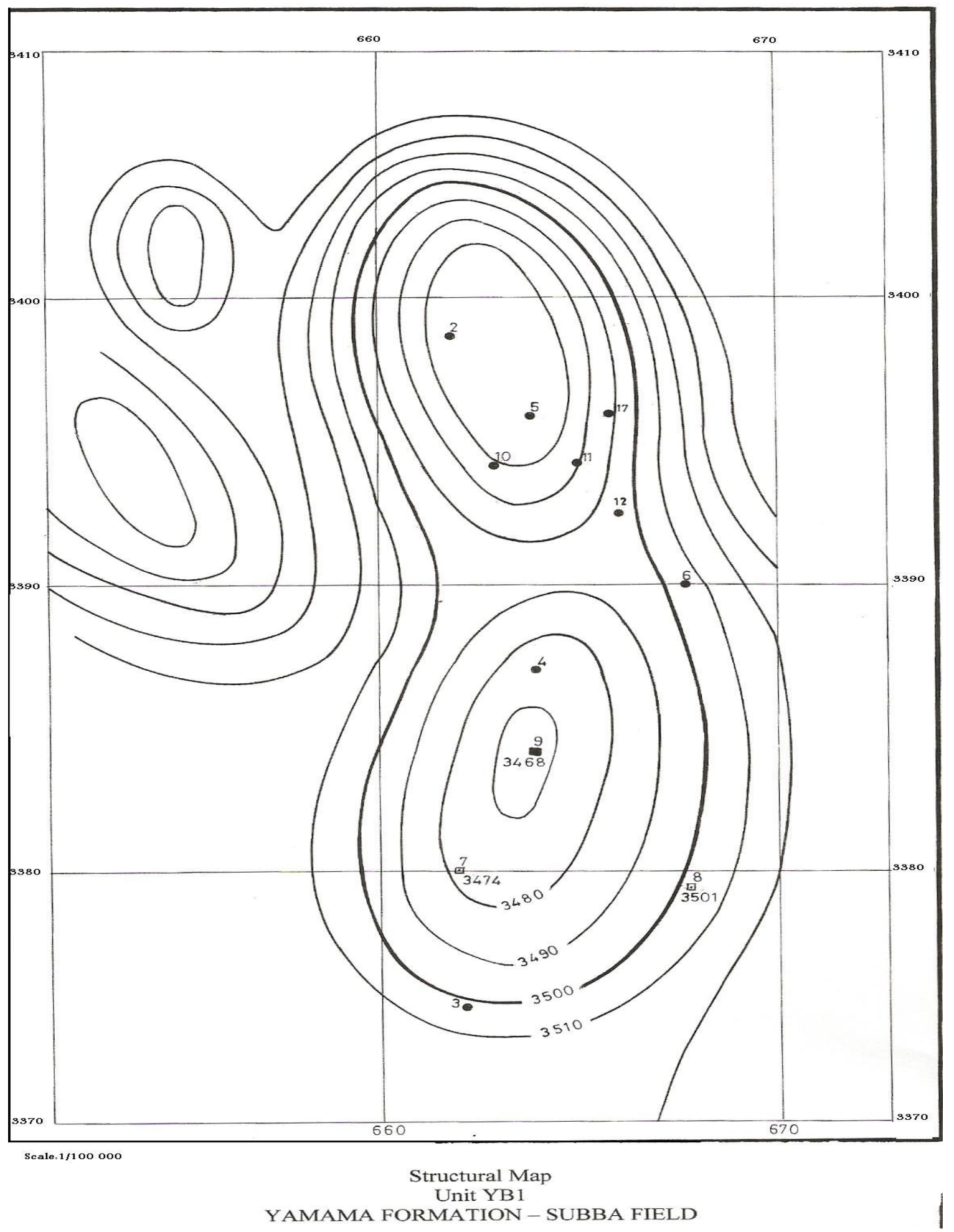

Fig (9B): Structure Contour Map on top of YB 


\section{RESERVOIR GEOLOGY}

\subsection{Reservoir Properties of Upper}

Yamama Member - (YA):

\subsubsection{Unit YA1:}

The thickness of this unit is uniformly-distributed around $(21 \mathrm{~m})$ over the southern dome of Subba field, it is composed of calcareous rocks of medium to high radioactive rates with low porosity in wells $\mathrm{Su}-7$ and 8 with high amount of clay content, whereas somewhat appositely improved in Su-9 of (6\%) porosity, and the spontaneous potential log reflects good permeability, thus the unit possessed an oil column only of $(1 \mathrm{~m})$ with $(5 \%$ phi) and (30\% Sw). Tables (3-8), Figs $(8,10-12)$.

\subsubsection{Unit YA-Barrier 1:}

The thickness of this unit is about $(5 \mathrm{~m}$.) at the apex of southern dome in the well Su-9 while there is an increasing at the two flanks, eastern and western, that thickness reaches to $(8 \mathrm{~m})$ in the wells $\mathrm{Su}-7$ and Su-8. The SP-log reflects distinctive positive deflection and the spectral gamma ray shows high radioactive proportions reflecting high dense compact lime mudstone facies. Tables (3-8), Figs (8, 10-12).

\subsubsection{Unit YA 2.1:}

It has a symmetrical thickness in the three wells (10-11m), comprises calcareous rocks with low porosity $\log$ recognition especially by SP and Sonic logs, the radioactive rates stays low to medium proportions, the permeability is poorly display due to clay materials abundance. There are few intervals have unsure economic oil potentialities, thickness of oil column did not exceed (1m.) with $(6 \%$ phi) and $(50 \% \mathrm{Sw})$. Tables (3-8), Figs (8, 10-12). 


\subsubsection{Unit YA-Barrier 2:}

The thickness of this unit reaches to $(7-8 \mathrm{~m})$ over three wells are penetrated in southern dome of Subba structure, the SP log display positive deflection and the gamma ray spectrometry gives high medium-high radioactive proportions, all these reflects high content of clay materials, but probably due to dolomitization some of few intervals improved their petrophysical properties thus they gave reservoir rocks contain oil with (7\% phi) in the well Su-9. Tables (3-8), Figs $(8,10-12)$.

\subsubsection{Unit YA 2.2:}

This unit of (22m) thickness, recognizes low porosity and permeability according to readings of SP and Sonic logs, the natural radioactive proportions of gamma ray $\log$ being low-medium but radioactive spectrometry of potassium is very low by uranium and thorium. The probably digenesis especially dolomitization and channels leaching processes made better intervals of this unit to being potential targets for future exploration thus they made oil column in (3m. thickness) with (5 $\%$ phi) and (35\% Sw). Tables (3-8), Figs $(8,10-12)$.

\subsubsection{Unit Barrier 3 (Main Barrier):}

The maximum thickness of this unit appears at the eastern flank of southern dome in the well Su-8 to reaches (19m) and somewhat decreases at the western flank $(17 \mathrm{~m})$. The porosity of this unit show low readings on $\mathrm{Sp}$ and Sonic logs, the permeability as well. The radioactive rates are high for $\mathrm{U}, \mathrm{K}$ and Th, but on the wells Su-8 and 9, are somewhat low. This unit contains porous beds with approximately (2m) thickness for each one in the well $\mathrm{Su}-8$ improves towards the crest of structure and 
have reservoir continuity with (11m) thickness ,theCPI shows hydrocarbon accumulations (7m) thickness with (7\% phi) and (26\% Sw) Tables(3-8 ), Figs( 8,10-12).

4.2. Reservoir Properties of Lower Yamama Member-(Main Unit YB)

\subsubsection{Unit YB1:}

The average thickness of this unit is bout $(30 \mathrm{~m})$, the low natural and spectral radioactive concentration where the clear permeable negative deflection of $\mathrm{Sp}$ log may consider as the diagnostic property for this unit. The porosity is more or less low on the well $\mathrm{Su}-7$ which locate close to western flank of southern dome whereas improve towards the crest and eastern flank where the oil column reaches to (9m.) in the well Su-9 with (7-8 \% phi ) and (32\% Sw) and (8m.) in the well $\mathrm{Su}-8$ with (9\% phi) and (44\% Sw) Tables(3-8 ), Figs( 8,10-12).

\subsubsection{Unit YB-Barrier 1:}

The average thickness of this unit reaches $(30 \mathrm{~m})$ and shows massive calcareous limestone where the Sonic log reflects low porosity, and high resistivity on Induction log ,the natural radioactive affect by gamma ray is high ,that is supported by spectrometry gamma ray as well, through the high concentration of uranium and medium concentration of both thorium and potassium . This unit contains in its lower part a few reservoir intervals with good porosity $(15 \%)$ especially on the well Su-8 which gave by DST (3450 B/D oil) with (42 API ) from oil column reached to $(6 \mathrm{~m})$ with $(11.2$ $\%$ phi) and (47.8\% Sw) Tables(3-8 ) , Figs( 8,10-12).

\subsubsection{Unit YB2.1:}

The thickness of this unit is ranges from $(7-17 \mathrm{~m})$ and the maximum be at the well Su-7 which located in western flank of structure (southern dome), consists of porous 


\section{Journal of Petroleum Research \& Studies}

calcareous limestone contains oolitic-pseudoolitic and peloidal facies. The porosity is clearly improve especially the intra-particle porosity type due to dissolution of drusy calcite cement during late diagenesis processes, consequently different types of vugs and fissures were formed to enhance this porosity especially at the well $\mathrm{Su}-8$ and in less grade at the two wells Su-7 and Su-9. The net oil column of this unit is $(7 \mathrm{~m}, 9 \mathrm{~m}, 6 \mathrm{~m})$ and the porosity $(8 \%, 12 \%, 10.8 \%)$ and water saturation $(8 \%, 27 \%, 23 \%)$ respectively. Tables(3-8 ) , Figs( 8,9-12).

\subsubsection{Unit YB-Barrier 2 :}

The thickness of this unit is increase at the crest of structure to reach $(24$ m.) in the well Su-9 and decrease towards flanks of dome to reach $(14 \mathrm{~m})$ in well $\mathrm{Su}-7$. The best petrophysical properties are in Su-9 position where the oil column reach to $(7 \mathrm{~m}$.) with (5-8 \% phi ) and ( $42-$ $60 \% \mathrm{Sw})$ while it has (3m.) oil column with $\quad$ (7-12\% phi) and (32-

$52 \mathrm{Sw}$ ) in the well $\mathrm{Su}-7$, but unfortunately, this unit was water impregnated because it is located under oil water contact. Tables (38), $\quad$ Figs $(8,9-12)$

\subsubsection{Unit YB 2.2:}

The unit range between(13 to $20 \mathrm{~m}$ ) in thickness with maximum value at the well $\mathrm{Su}-8$ on the eastern flank, it consists porous calcareous rocks with high quality of petrophysical properties in all three wells due to low content of clay materials and high porosity where reach to $(10-13 \%)$, the sedimentary facies are of medium-good sorted peloids. The net oil column of this unit in the well Su-7 is (7m) with (10\% phi) and $(31 \% \mathrm{Sw})$, the production test revealed (500-1000 $\mathrm{BO} / \mathrm{D}$ rate) and (36degree-API) The CPI logs shows that the well Su-9 may contain hydrocarbon accumulation with (13m thickness) and $(10 \%$ phi) and $(40 \% \quad \mathrm{Sw})$ Tables(3-8 ), Figs( 8,10-12). 


\subsubsection{Unit Barrier 3:}

\section{The sonic-log readings for}

this unit reflect a barrier unit, very poor property. The unit recognizes high rates of both natural and spectral gamma ray where the spectrometry gamma ray log gives high proportions of uranium especially in the lower part of the unit, the thickness reaches to $(18 \mathrm{~m})$, thus the unit has not contain any reservoir rocks. Tables(3-8 ), Figs( 8,9-12).

\subsubsection{Unit YB3:}

The thickness is between (13-

$22 \mathrm{~m}$ ), the gamma ray logs readings reveal low content of clay materials at the wells $\mathrm{Su}-7$ and Su-9 while these readings relatively reflect high radioactive proportions in the well
$\mathrm{Su}-8$. The $\operatorname{logs}$ behaviors indicate that the unit is located below oil water contact which had been enhanced by the result of drill stem test where gave water in the well $\mathrm{Su}$ 7.Tables(3-8 ), Figs( 8,10-12).

\subsubsection{Unit Barrier 4:}

The unit is taken as a hard massive barrier rocks where the porosity is strictly reduce in all wells, the thorium and potassium spectrometry relatively reflect low amount of clay materials but high amount of uranium spectrometry which gives an indicator that the unit was deposited under a weak energy of deposition, the lower part of this unit had been taken before the shaly - clayey rocks of Sulaiy formation, hence the thickness of this unit will so thick (70-78m) . Tables (38),Figs(8,10-12) . 


\section{Journal of Petroleum Research \& Studies}

Table (3): Petrophysical Properties of Yamama Units, well Su-7

\begin{tabular}{|c|c|c|c|c|c|}
\hline $\begin{array}{c}\text { Interval } \\
\text { (m) }\end{array}$ & Unit & $\begin{array}{c}\text { Net Pay } \\
\text { (m) }\end{array}$ & $\begin{array}{l}\text { Phi } \\
(\%)\end{array}$ & $\begin{array}{l}\mathrm{Sw} \\
(\%)\end{array}$ & Remarks \\
\hline $3548.5-3551.5$ & YB1 & 3 & 10 & 45 & * D.S.T \\
\hline $3552.5-3553.5$ & $"$ & 1 & 11 & 46 & carmed out \\
\hline $3571.5-3574.5$ & $"$ & 3 & 13 & 50 & . \\
\hline $3585.5-3585.8$ & Barr.1 & 0.3 & 9 & 58 & $\begin{array}{c}\text { zone of } \\
\text { Barr.1 }\end{array}$ \\
\hline $3588.9-3589.6$ & $"$ & 0.7 & 9 & 43 & resulted in \\
\hline $3590-3590.7$ & " & 0.7 & 12 & 52 & $\begin{array}{l}\text { producing of } \\
\text { oil with }\end{array}$ \\
\hline $3593-3594.3$ & $"$ & 1.3 & 9 & 50 & $\begin{array}{l}\text { un average } \\
\text { (3450 B/D) }\end{array}$ \\
\hline $3597.5-3598.5$ & $"$ & 1 & 6 & 42 & $\mathrm{API}=42$ \\
\hline $3599.5-3601.5$ & $"$ & 2 & 12 & 42 & $\begin{array}{l}* * \text { D.S.T } \\
\text { carried out }\end{array}$ \\
\hline $3605.5-3615.5$ & YB2.1 & 9.5 & 12 & 27 & $\begin{array}{l}\text { the same unit } \\
\text { but at higher } \\
\text { lithological } \\
\text { zone ,the test } \\
\text { was dry }\end{array}$ \\
\hline
\end{tabular}




\section{Journal of Petroleum Research \& Studies}

\begin{tabular}{|c|c|c|c|c|c|}
\hline $\begin{array}{l}\text { Interval } \\
\text { (m) }\end{array}$ & Unit & $\begin{array}{c}\text { Net Pay } \\
\text { (m) }\end{array}$ & $\begin{array}{l}\text { Phi } \\
(\%)\end{array}$ & $\begin{array}{l}\mathrm{Sw} \\
(\%)\end{array}$ & Remarks \\
\hline $3533-3534$ & YB1 & 1 & 11 & 30 & \multirow{6}{*}{$\begin{array}{l}\text { The result } \\
\text { of } \\
\text { production } \\
\text { test for } \\
\text { unit (YB1) } \\
\text { ) }\end{array}$} \\
\hline $3544.5-3545$ & YB(Barr.1) & 0.5 & 5 & 40 & \\
\hline $3548-3548.5$ & " & 0.5 & 8 & 35 & \\
\hline $3551.5-3552.5$ & " & 1 & 7 & 46 & \\
\hline $3556.5-3557.5$ & " & 1 & 9 & 46 & \\
\hline $3562-3563.5$ & YB2.1 & 1.5 & 7 & 55 & \\
\hline $3569.5-3570.5$ & $"$ & 1 & 7 & 60 & $\begin{array}{c}\text { Gave } \\
(500-1000\end{array}$ \\
\hline $3572-3577$ & " & 5 & 15 & 52 & B/D) oil \\
\hline $3577.5-3579.5$ & " & 2 & 12 & 48 & $\begin{array}{c}\text { with } \\
\text { API }=26^{0}\end{array}$ \\
\hline $3580-3580$ & YB(Barr.2) & 1 & 6 & 46 & While \\
\hline $3581.5-3582.5$ & " & 1 & 12 & 35 & $\begin{array}{l}\text { gave water } \\
\text { from unit }\end{array}$ \\
\hline $3684-3585.5$ & $"$ & 1.5 & 8 & 52 & (YB2) \\
\hline $3591.5-3592$ & $"$ & 0.5 & 7 & 60 & \\
\hline $3593.5-3600.5$ & YB2.2 & 7 & $9-12$ & 35 & \\
\hline
\end{tabular}

Table (4) Petrophysical Properties of Yamama Units, well Su-8 


\section{Journal of Petroleum Research \& Studies}

Table (5) Petrophysical Properties of Yamama Units ,well Su-9

\begin{tabular}{|c|c|c|c|c|c|}
\hline Interval & Unit & Net & Phi & Sw & Remarks \\
\hline $3405-3406$ & YA1 & 1 & 6 & 30 & \multirow{22}{*}{$\begin{array}{l}\text { * Failed DST } \\
\text { @ unit YB1 } \\
\text { due to non- } \\
\text { seating packer } \\
\text { ** Failed DST } \\
\text { @ unit YB2 } \\
\text { due to } \\
\text { breakdown }\end{array}$} \\
\hline $3438-3439$ & YA2.1 & 1 & 7 & 50 & \\
\hline $3446-3446.5$ & $=$ & 0.5 & 6 & 32 & \\
\hline $3460-3365$ & YA2.2 & 4 & 6 & 35 & \\
\hline $3477.5-3479.5$ & YA/ & 2 & 11 & 30 & \\
\hline $3481-3493.5$ & Barr.3-YB1 & 12.5 & 11 & 30.8 & \\
\hline $3496-3497.5$ & YB1 & 1.5 & 6 & 45 & \\
\hline $3500-3505.5$ & $=$ & 5.5 & 8 & 43 & \\
\hline $3517-3519$ & $=$ & 2 & 7 & 33 & \\
\hline $3519.5-3523.5$ & $=$ & 4 & 10 & 35 & \\
\hline $3531-3532$ & YB/ Barr.1 & 1 & 5 & 50 & \\
\hline $3533-3534$ & $=$ & 1 & 9 & 45 & \\
\hline $3537-3538$ & $=$ & 1 & 8 & 42 & \\
\hline $3539-3540$ & $=$ & 1 & 9 & 45 & \\
\hline $3550-3553.5$ & YB2.1 & 3.5 & 16 & 25 & \\
\hline $3555-3556.6$ & $=$ & 1.5 & 18 & 20 & \\
\hline $3558-3561$ & YB/Barr.2 & 3 & 6 & 42 & \\
\hline $3567-3570$ & $=$ & 3 & 6 & 20 & \\
\hline $3581-3682$ & $=$ & 1 & 5 & 52 & \\
\hline $3582-3585$ & $=\mathrm{YB} 2.2$ & 3 & 12 & 48 & \\
\hline $3586-3590$ & $=$ & 4 & 9 & 46 & \\
\hline $3591-3597$ & $=$ & 6 & 9 & 46 & \\
\hline
\end{tabular}


Table (6) Net results - Well Su-7

\begin{tabular}{|c|c|c|c|}
\hline Unit & Net Pay $(\mathrm{m})$ & Phi $(\%)$ & Sw (\%) \\
\hline YB1 & 1 & 11 & 30 \\
\hline YB / Barr.1 & 3 & 7.25 & 42 \\
\hline YB2.1 & 9.5 & 10.25 & 52 \\
\hline YB/ Barr.2 & 4.3 & 8.25 & 48 \\
\hline YB2.2 & 7 & 10 & 31 \\
\hline
\end{tabular}

Table (7) Net results - Well Su-8

\begin{tabular}{|c|c|c|c|}
\hline Unit & Net Pay $(\mathrm{m})$ & Phi $(\%)$ & Sw $(\%)$ \\
\hline YB1 & 7 & 11.3 & 47 \\
\hline YB / Barr.1 & 6 & 9.5 & 47.8 \\
\hline YB2.1 & 9.5 & 12 & 27 \\
\hline
\end{tabular}

Table (8) Net results - Well Su-9

\begin{tabular}{|c|c|c|c|}
\hline Unit & Net Pay $(\mathrm{m})$ & Phi $(\%)$ & Sw (\%) \\
\hline YA1 & 1 & 6 & 30 \\
\hline YA2.1 & 1.5 & 6.5 & 41 \\
\hline YA2.2 & 4 & 6 & 35 \\
\hline YA / Barr.3 & 10 & 9.5 & 29 \\
\hline YB1 & 17.5 & 8 & 37.5 \\
\hline YB / Barr.1 & 4 & 7.75 & 45.5 \\
\hline YB2.1 & 5 & 17 & 35 \\
\hline YB / Barr.2 & 7 & 5.5 & 38 \\
\hline YB2.2 & 13 & 10.3 & 44 \\
\hline
\end{tabular}


Su-7

Fm. : Yamama

R.T.K.B $=31.4 \mathrm{~m}$

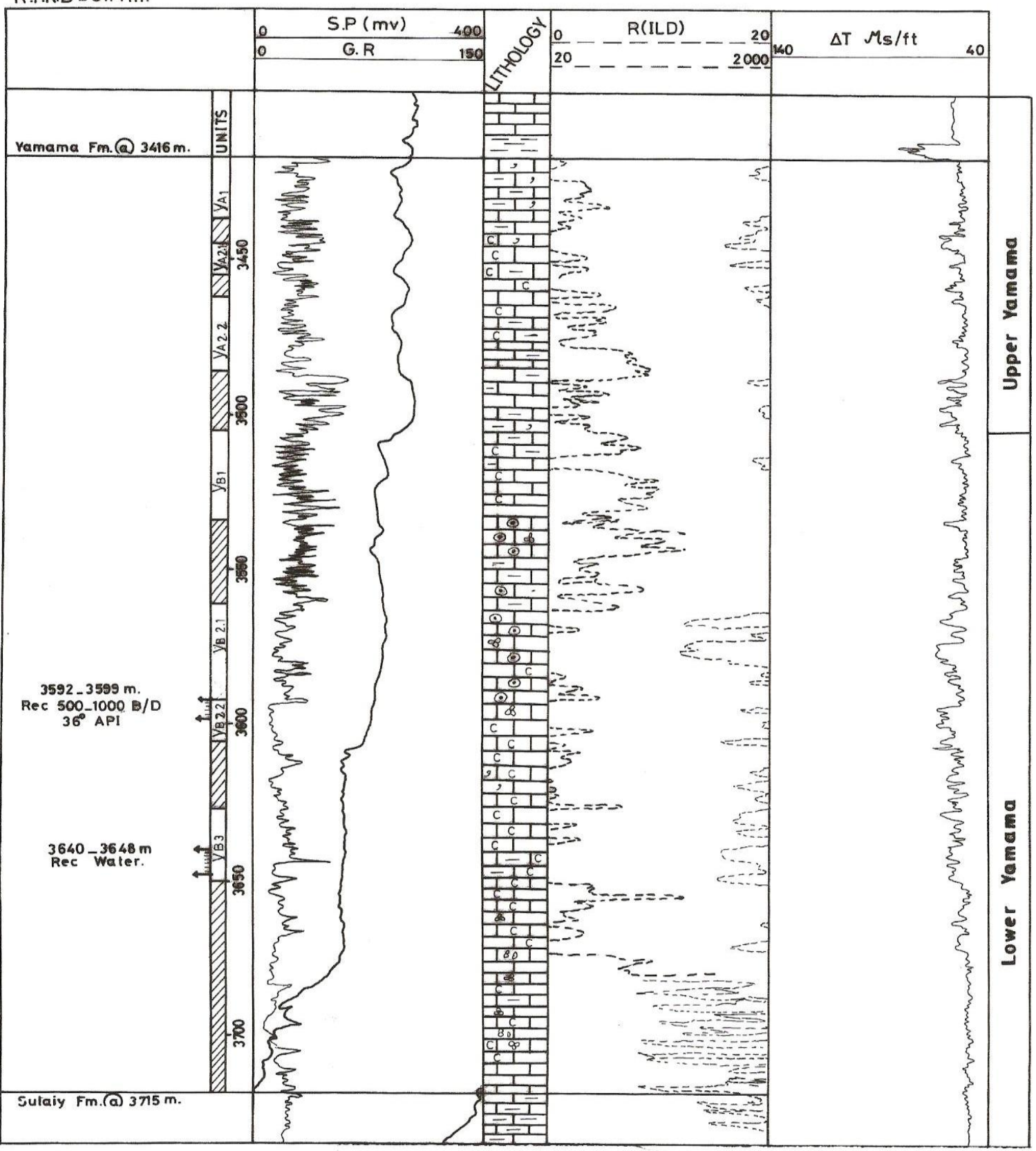

Fig (10-A) Conventional composite well section - Well Su - 7 


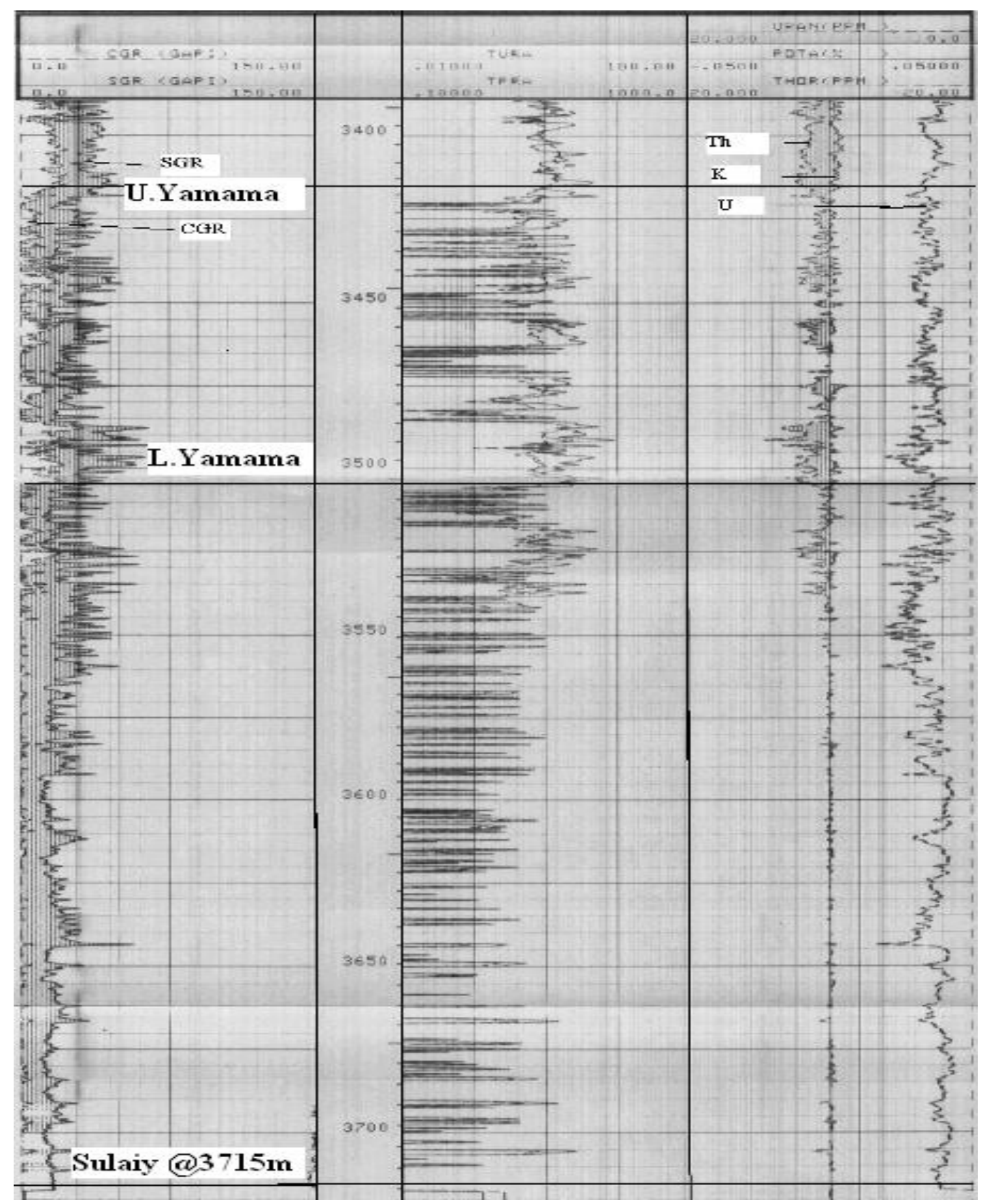

Figure (10-B) Spectrometry Composite Well Log Su- 7 


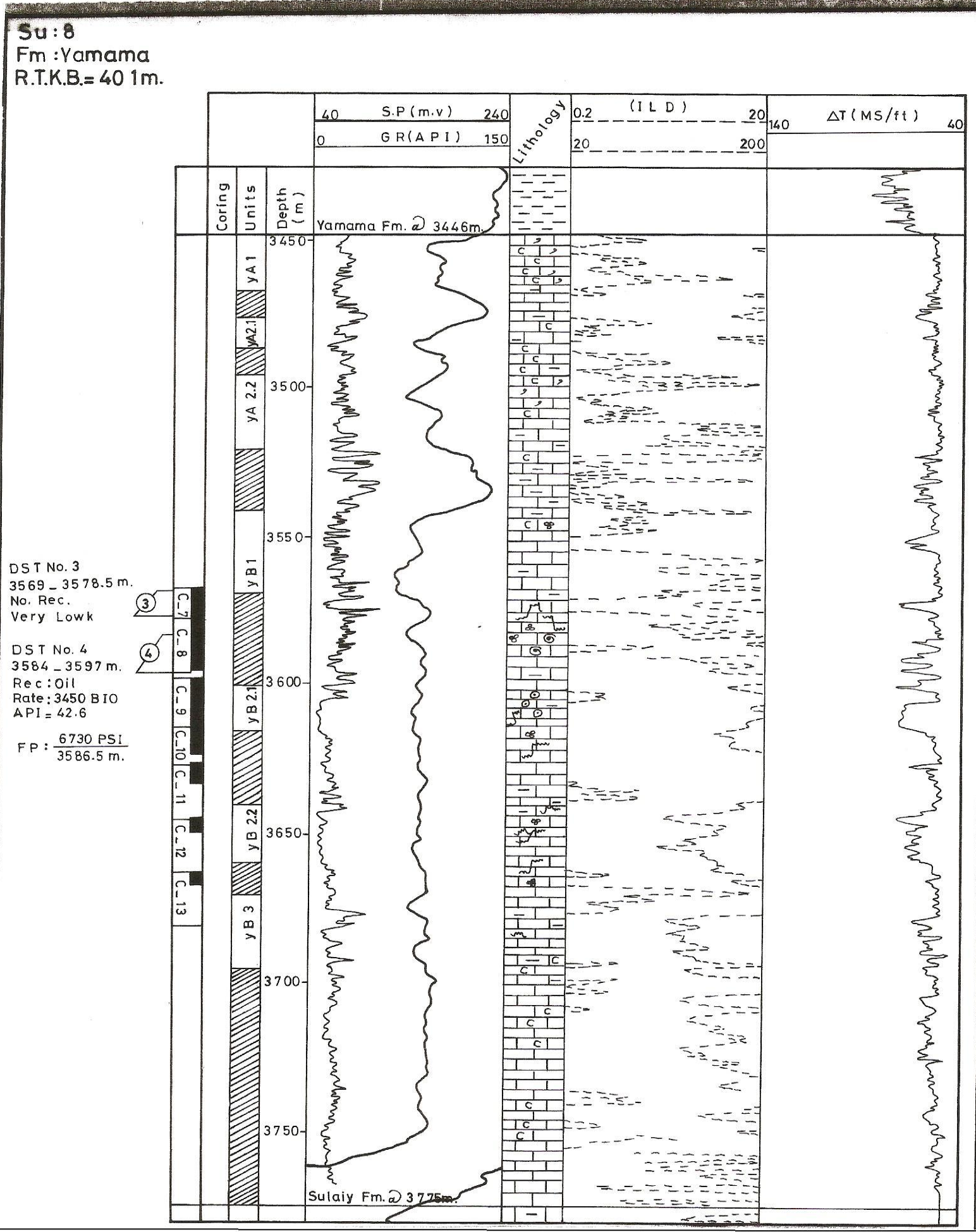

Fig (11-A) Conventional composite well section - Well $\mathrm{Su}-8$ 


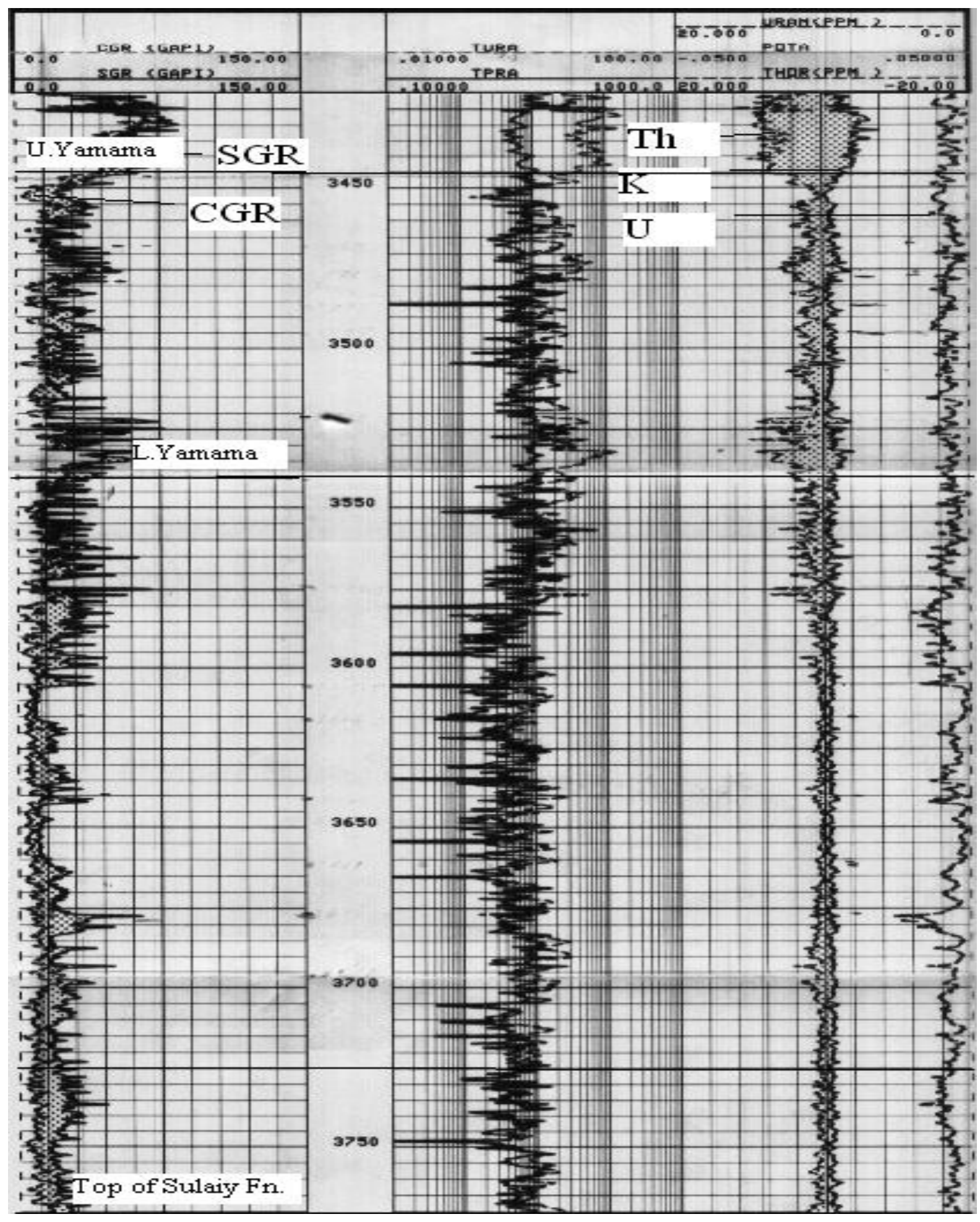

Fig (11-B) Spectrometry Composite Well Log Su- 8 


\section{Journal of Petroleum Research \& Studies}

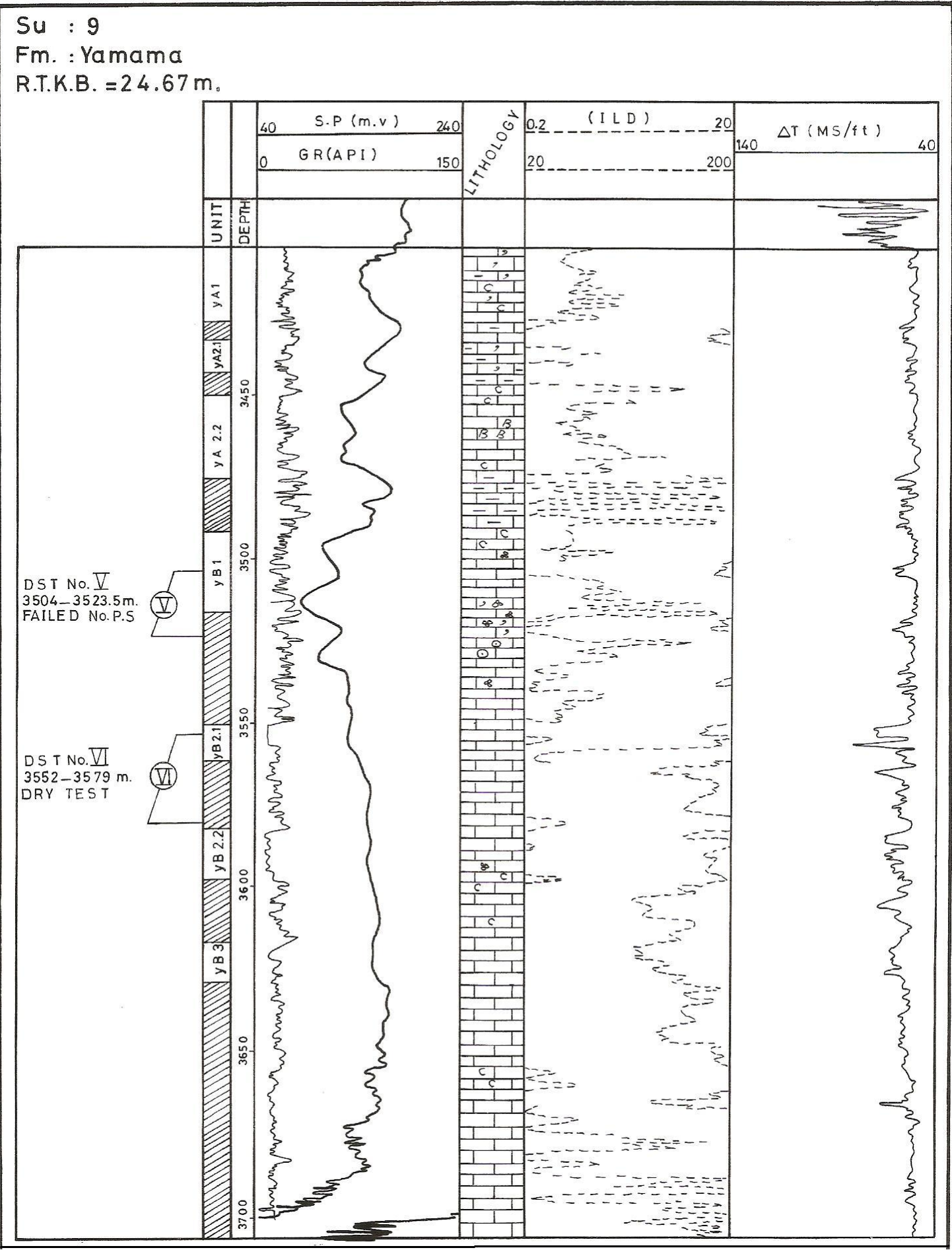

Fig (12-A) Conventional composite well section - Well $\mathrm{Su}-9$ 


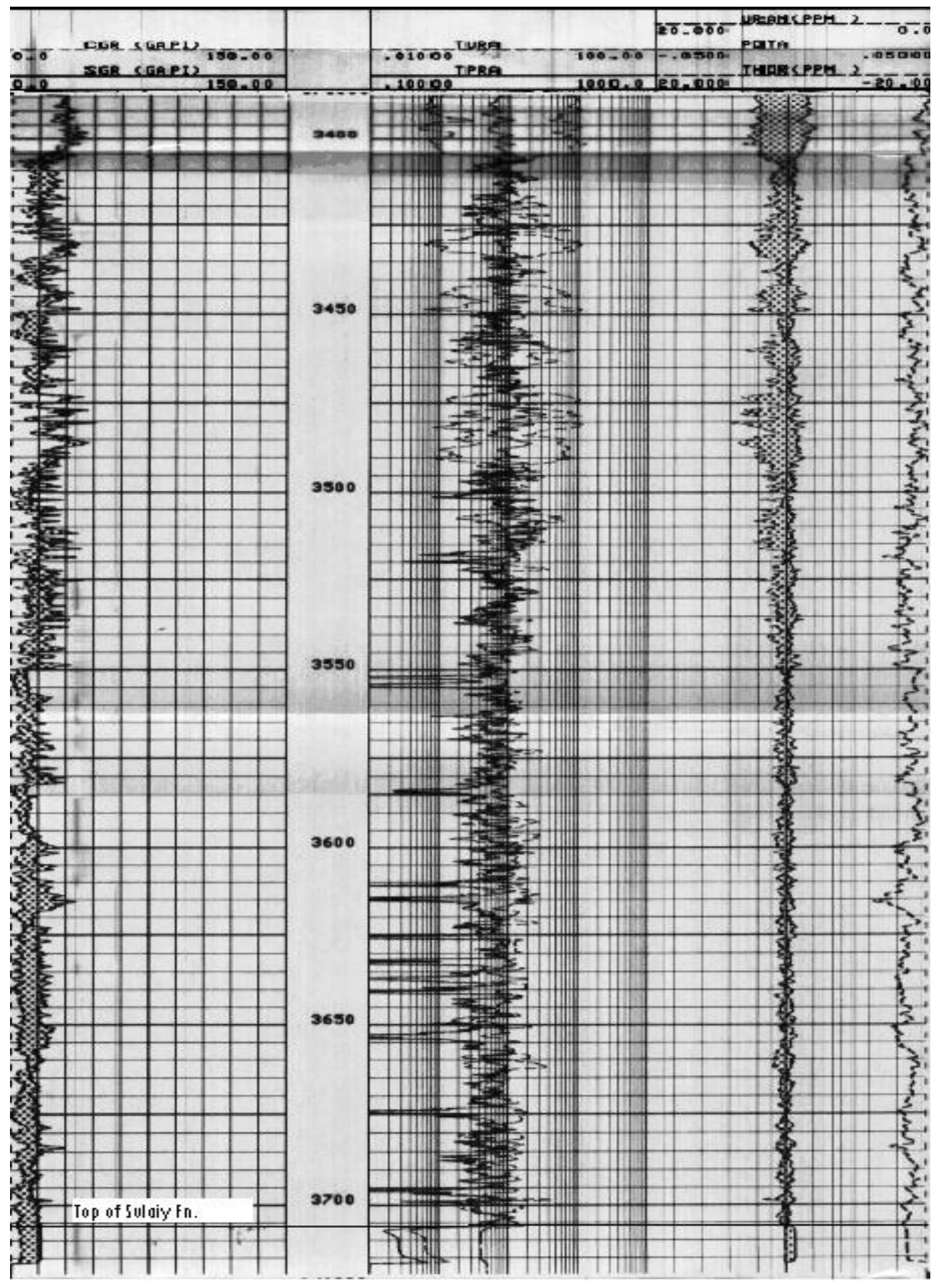

Fig (12-B) Spectrometry Composite Well Log Su- 9 


\subsection{DETERMINATION OF OIL}

\section{WATER CONTACT}

\section{According to electrical $\operatorname{logs}$} monitoring, well log interpretation and test results carried out the formation units, all these data showed that the oil water contact can be determined in the main reservoir (lower Yamama ) in the well Su-9 at depth $3597 \mathrm{~m}$ (3572m MSL) at the end of reservoir unit (YB2.2) on the basis of water saturation increasing.

This unit and in the well Su-7 it has an oil column $(3593.5-3600.5$ m) and the CPI logs did not show hydrocarbon accumulation on interval (3600-3603 m.) which has very low porosity and the production test which carried the units (YB3 Barrier 3) was gave water, hence we can determine the oil water contact in the well su-7 at depth $(3571.6 \mathrm{~m}$ MSL) and at the same reservoir unit.

In the well Su-8 which low structurally than last two wells, its possible to elect the depth $(3574.9 \mathrm{~m}$ MSL) at the end of reservoir unit (YB2.1), in the light of this, its possible to take the oil water contact in the lower Yamama at depth 3573m (MSL) for southern dome of Subba field. Figure (12). 


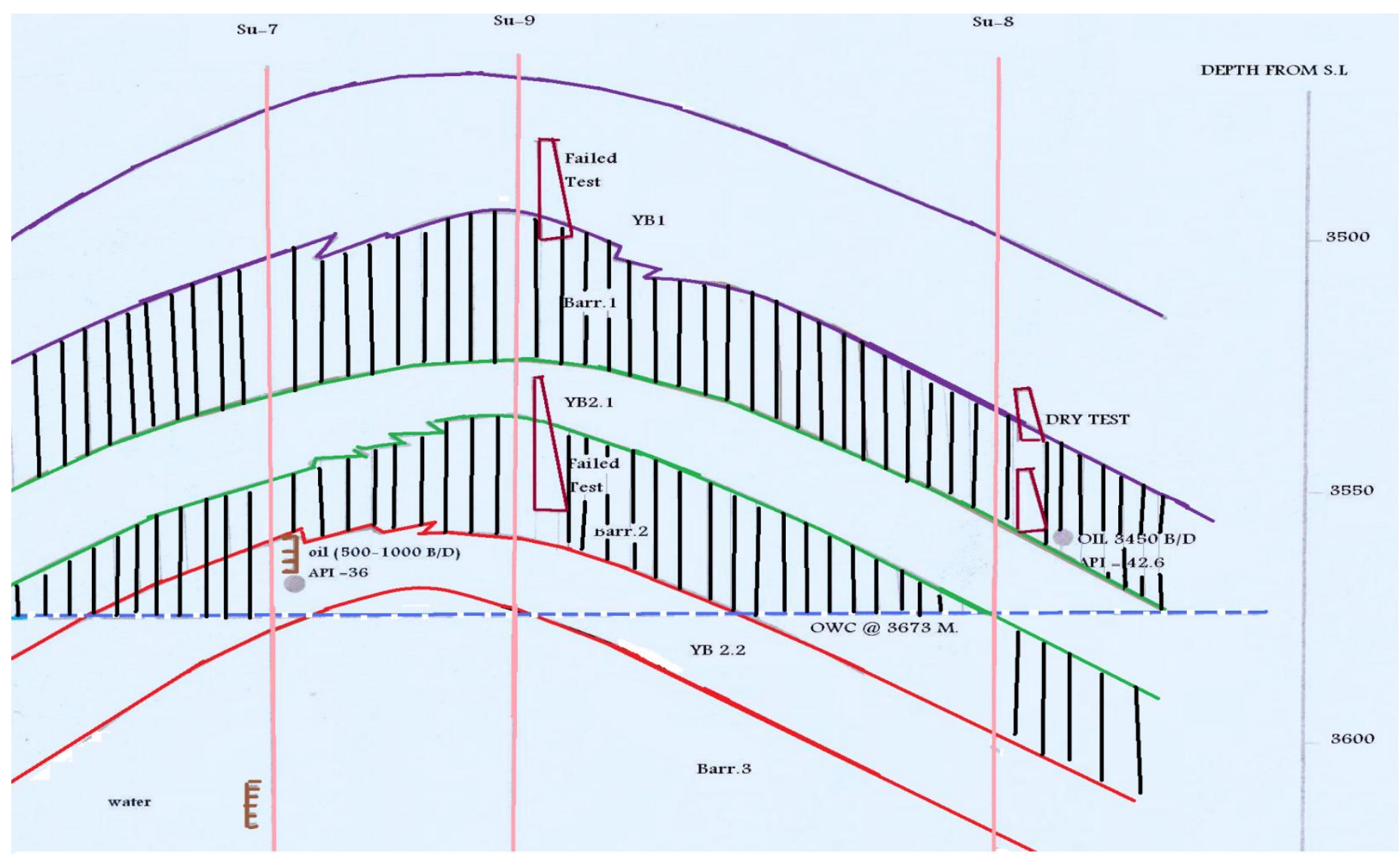

Fig (12) Oil Water Contact of Yamama formation -Subba Field 


\section{Conclusions}

1- The structural picture of Subba field showed that the Subba field on top of Yamama formation consists of two main domes (northern and southern), the Yamama wells allocate on southern one.

2- The top of Yamama formation is taken as the basis of the first appearance of porous clean limestone with fossiliferous aggregates below the shale or shaly limestone of Ratawi formation.

3- The formation was deposited under a regressive phase due to slowly gradational uplift of the basin which began from deposition of upper part of Sulaiy formation to the end of Yamama formation.

4- The formation is divided into two main reservoir units each one contains both reservoir and barrier subunits.

5- The lower Yamama member (YA) consider as the main reservoir unit and the subunits (YB1\&YB2) are the best reservoir units in the formation, represented by pseudoolitic-oolitic packestone / grainstone.

6- Few of barrier subunits contains good reservoir rocks where produced oil in the well Su-8.

7- On the basis of electrical logs and water saturation degree, the oil / water contact can be assign at $3572 \mathrm{~m}$. (MSL) of the main reservoir unit (YB) in the well Su-9 but it is not clear in the wells Su-7 and Su-8. 


\section{REOMMENDATIONS}

1- Because of drilling lacking in the northern dome of the field, the study recommends to drill an appraisal well in that dome after a new 3D seismic survey, and / or deepening the wells $\mathrm{Su}-2,5$, and 10 to Yamama formation.

2- Coverage entirely the Yamama formation with (50 m) above and below by coring, to determine in a certain manner the reservoir facies and facies change vertically and horizontally over the field and adjacent ones.

3- It is very important to reduce the thickness of tested intervals; this technique will assist us to compare the test results with well logs interpretation and core description - analysis.

4- After implementing the above, it is necessary to use the advanced software programs in geological and reservoir studies and consequently well management. 


\section{REFERENCES}

1- Alebrahimi, A.T., 1999, Geological study of Yamama formation in Subba field. SOC-Basrah.

2- Fulloria, 1976, Petroleum prospects of Yamama formation in Southern Iraq, Baghdad.

3- Hussain, M., F., Biden, E., A., 1996, Geological report on Yamama reservoirs -Subba field, Basrah.

4- Razoian, A.M., 1979, Geology of Yamama formation in Ratawi oil field. SOC- Basrah.

5- Razoian, A.M., 1996, Geological study of Yamama formation in southern Iraq. SOC- Basrah.

6- Serra, O., Baldwin, J., Quirein, J., 1972 Theory, Interpretation and Practical Application of Gamma Ray Spectrometry, Paris.

7- Oil Exploration Company, 1989, Geological report on Yamama reservoirs - Subba field, Baghdad.

8- Oil Exploration Company, 1992, Seismic Re-Interpretation, Subba-Luhais structures, Baghdad.

9- Oil Exploration Company, 1988, Final Report on Seismic reinterpretation-Subba Luhais structures, Baghdad.

10- Primary geological reports of the wells Su-7, 8, 9, Basrah.

11- Final geological reports of the wells Su-7, 8, 9, Basrah.

12- CPI of wells Su-7, 8, 9. 
13- Technical Report No.747, physical and thermodynamic properties of Yamama oil in the well Su-7.

14- Schlumberger.1976, Principals of open hole log interpretation.

15- Schlumberger, 1996 open hole log interpretation.

16- Schlumberger, 1989, Gamma ray Spectrometry tool.

17- Schlumberger, 1986, Advance open hole logs interpretation. 